\title{
Totally endoscopic mobilization of a patent left internal thoracic artery graft from the sternum through the left hemithorax in redo coronary artery surgery: A new approach
}

\author{
Tomonobu Abe, MD, ${ }^{\mathrm{a}}$ Tetsuo Taniguchi, MD, ${ }^{\mathrm{b}}$ Takafumi Terada, MD, ${ }^{\mathrm{a}}$ and Hajime Sakurai, MD, ${ }^{\mathrm{a}}$ \\ Nagoya, Japan
}

In redo coronary artery bypass grafting (CABG) procedures, the patent left internal thoracic artery (LITA) graft is at risk of reentry injury when it adheres to the sternum. ${ }^{1}$ We herein report a new approach to dissect the LITA graft from the sternum using video-assisted thoracoscopic surgery (VATS) through the left hemithorax.

\section{CLINICAL SUMMARY}

A 63-year-old man was referred to undergo redo CABG for newly developed class 3 angina. The patient had undergone first-time CABG with a LITA to the left anterior descending coronary artery (LAD), a left radial artery graft to the obtuse marginal artery, and the right gastroepiploic artery to the posterior descending artery 8 years before his presentation in our department. The current coronary angiogram showed $90 \%$ stenosis of the LITA graft and occlusion of the right gastroepiploic artery. The radial artery graft was patent. The native LAD was totally occluded, so that the blood supply to the whole anterior wall was completely dependent on the diseased LITA graft. Redo double CABG was recommended for the patient.

Preoperative computed tomography showed the LITA graft crossing the sternal midline and adherence to the manubrium (Figure 1). To avoid injury to the patent LITA graft, we planned to do a presternotomy dissection of the LITA graft from the sternum by VATS.

General anesthesia was induced, and a double-lumen endotracheal tube was inserted. The patient was placed in a supine position, and the left arm was abducted. A camera port was created in the fifth intercostal space in the anterior axillary line (Figure 2, $A$ ). A thoracoscope was carefully inserted. There were minimal adhesions in the left side of the thorax. The LITA graft was immediately identified under

From the Department of Cardiovascular Surgery a and General Thoracic Surgery, Chukyo Hospital, Nagoya, Japan.

Disclosures: Authors have nothing to disclose with regard to commercial support.

Received for publication Jan 1, 2011; revisions received Jan 30, 2011; accepted for publication Feb 22, 2011; available ahead of print April 1, 2011.

Address for reprints: Tomonobu Abe, MD, Department of Cardiovascular Surgery, Chukyo Hospital, 1-1-10 Sanjyo, Minami-ku, Nagoya, 457-8510, Japan (E-mail: tomonobu_abe@chukyo-hosp.jp).

J Thorac Cardiovasc Surg 2011;142:946-8

$0022-5223 / \$ 36.00$

Copyright (C) 2011 by The American Association for Thoracic Surgery

doi: $10.1016 /$ j.jtcvs.2011.02.029

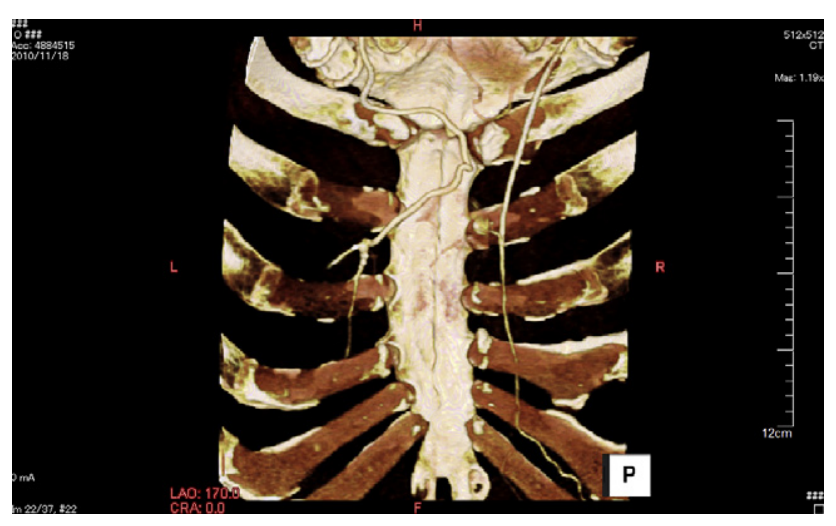

FIGURE 1. Three-dimensional reconstructed computed tomographic images showed that the patent left internal thoracic artery graft crossed over the sternal midline and adhered to the posterior wall of the manubrium.

the parietal pleura as it descended vertically from the upper limit of the thorax and then changed its course parallel to the costae from left to right, running into the retrosternal fat tissue (Figure 2, B). Two other working ports were created in the third and fourth intercostal spaces. The LITA was dissected using ultrasonic scalpels from left to right (Figure 2, $C$ ) over the midline. The LITA graft strongly adhered to the chest wall as is usually observed, and it was mobilized by pushing the ultrasonic scalpel against the periostium where adhesion was very dense. Visualization was good throughout the procedure. Although we considered performing thoracotomy in case the endoscopic dissection proved to be too difficult, it turned out not to be necessary. A redo sternotomy was done using an oscillating saw. No reentry injury occurred.

The right internal thoracic artery was harvested. The heart was dissected. After establishment of cardiopulmonary bypass and administration of cardioplegia, myocardial revascularization was performed with the right internal thoracic artery to the distal LAD and a saphenous vein graft to the posterolateral branch from the right coronary artery. The patient's postoperative course was uneventful.

\section{DISCUSSION}

Most candidates for reoperative $\mathrm{CABG}$ require a median sternotomy to be completely revascularized. However, sternal reentry by an oscillating saw, which is primarily a blind 

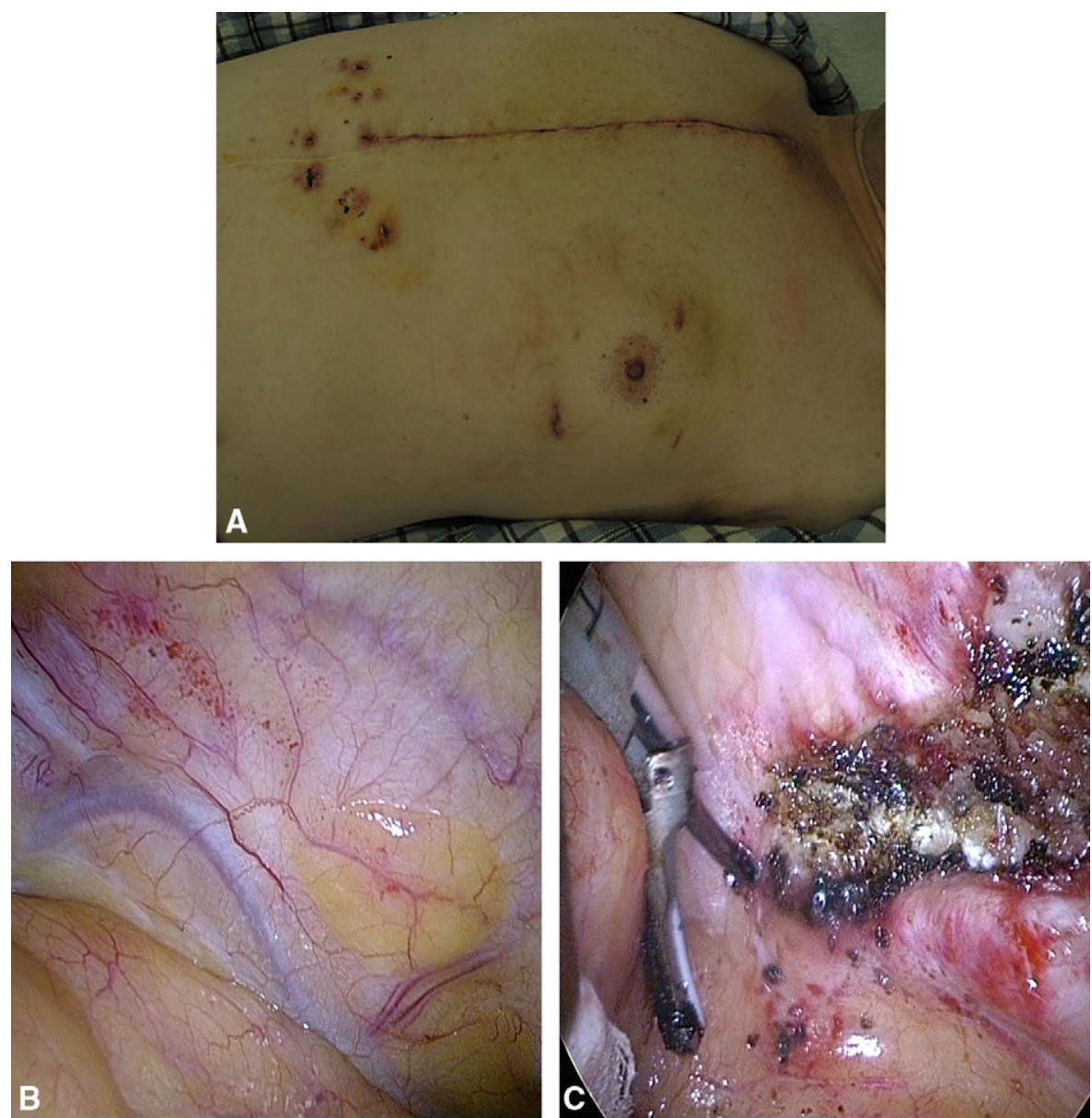

FIGURE 2. A, Postoperative picture of chest wounds showing the position of the ports used for video-assisted thoracic surgery. The lowest incision in the fifth intercostal space in the anterior axillary line was used for the camera port. The other 2 higher incisions were used as working ports. B, Intraoperative image of the video thoracoscope. The left internal thoracic artery graft was readily seen under the parietal pleura. It descended vertically from the upper limit of the thorax and then changed its course parallel to the costae from the left to right, running into the retrosternal fat tissue behind the manubrium. $\mathrm{C}$, Intraoperative image of the video thoracoscope. The left internal thoracic artery graft was dissected from the chest wall and the sternum using ultrasonic scalpels.

procedure, places the patient at high risk of injury to the graft. $^{2}$ This risk is even higher when there is radiographic evidence of adherence of the patent LITA grafts to the sternum. $^{1}$

In addition to various strategies to reduce the risk of injury with blind resternotomy, ${ }^{2,3}$ there have been a couple of reports of retrosternal dissection under direct vision., Gazzaniga and Palafox ${ }^{4}$ reported retrosternal dissection from a subxiphoid incision guided by a thoracoscope in mixed redo cases. However, adhesion of the LITA grafts usually occurs at the very upper part of the sternum, where visualization and dissection maneuvers by the subxiphoid approach are not easy to achieve. Ismail and colleagues ${ }^{5}$ reported retrosternal adhesiolysis through a right anterior minithoracotomy. This worked well, but the LITA graft could not be directly seen. In contrast, it could be readily seen from the left hemithorax. The LITA grafts are adherent to the sternum because they have been pushed by the left lungs in these cases. ${ }^{1}$ When we consider this mechanism, it is easy to understand why the LITA grafts can be better observed and are more approachable from the left hemithorax.

Because the left pleura is often entered during LITA harvesting, some cases may demonstrate significant adhesion in the left hemithorax. Although usual loose adhesion can be managed by VATS, a small left thoracotomy could be an option in difficult cases.

In conclusion, totally endoscopic mobilization of a patent LITA graft from the sternum through the left hemithorax facilitates safe redo sternotomy. The identification of the LITA graft is easy with this approach.

\section{References}

1. Gillinov AM, Casselman FP, Lytle BW, Blackstone EH, Parsons EM, Loop FD, et al. Injury to a patent left internal thoracic artery graft at coronary reoperation. Ann Thorac Surg. 1999;67:382-6.

2. Follis FM, Pett SB Jr, Miller KB, Wong RS, Temes RT, Wernly JA. Catastrophic hemorrhage on sternal reentry: still a dreaded complication? Ann Thorac Surg. 1999;68:2215-9. 
3. Aris A. Controlled exsanguination during sternal reentry. J Thorac Cardiovasc Surg. 2003;126:918-9.

4. Gazzaniga AB, Palafox BA. Substernal thoracoscopic guidance during sternal reentry. Ann Thorac Surg. 2001;72:289-90.
5. Ismail I, Zhang R, Ringe K, Fischer S, Haverich A. Retrosternal adhesiolysis through an anterior minithoracotomy: a novel approach facilitating complete median redo sternotomy with a patent internal thoracic artery graft. $J$ Thorac Cardiovasc Surg. 2009;137:1034-5.

\title{
Secure anastomosis for damaged aortic root reconstruction: Graft insertion technique
}

\author{
Yoshitsugu Nakamura, MD, ${ }^{a}$ Osamu Tagusari, MD, ${ }^{a}$ Junjiro Kobayashi, MD, ${ }^{\mathrm{b}}$ and Hiroyuki Nakajima, MD, ${ }^{\mathrm{b}}$ \\ Tokyo and Osaka, Japan
}

Bleeding from the proximal anastomosis is a devastating complication after aortic root replacement. Especially in situations requiring reoperation of the aortic root or situations involving prosthetic valve endocarditis (PVE), damage, an irregularly shaped annulus, or inflammation in the surrounding tissue makes the proximal anastomosis technically demanding. ${ }^{1,2}$ We describe a novel graft insertion technique that can be used in such complicated cases. Our technique provides a reliable double-suture placement to reinforce the proximal anastomosis.

\section{CLINICAL SUMMARY}

Through a median sternotomy, the aortic root is dissected, and cardiopulmonary bypass is established in the usual manner. After crossclamping of the aorta, the prosthesis is removed, and coronary ostia are trimmed. In cases of PVE, aggressive debridement of the infected tissue around the aortic root is carried out. An inverted tube graft with a diameter the same as that of the left ventricular outflow tract (LVOT) and a length of $3 \mathrm{~cm}$ is inserted into the LVOT (Figures 1, $A$, and 2, A). Nine to 12 horizontal mattress sutures are placed from inside the inserted graft to the epicardial side with $2-0$ synthetic braided and pledgeted sutures (Figure 1, B). Then the seam is reinforced with running over-and-over suturing of the edges of the LVOT and the graft with 4-0 polypropylene sutures (Figures $1, C$, and 2, B). This completes a double-suture reconstruction for the proximal anastomosis. Next, the tube graft inserted into the LVOT

From the Department of Cardiovascular Surgery, ${ }^{\mathrm{a}}$ NTT Medical Center, Tokyo; and the Department of Cardiovascular Surgery, ${ }^{\mathrm{b}}$ National Cerebral and Cardiovascular Center, Osaka, Japan.

Disclosures: Authors have nothing to disclose with regard to commercial support.

Received for publication Jan 8, 2011; revisions received Feb 15, 2011; accepted for publication Feb 25, 2011; available ahead of print April 1, 2011.

Address for reprints: Yoshitsugu Nakamura, MD, Department of Cardiovascular Surgery, NTT Medical Center Tokyo, 5-9-22 Higashigotanda, Shinagawa-ku,

Tokyo 141-8625, Japan (E-mail: ystgnkmr@gmail.com).

J Thorac Cardiovasc Surg 2011;142:948-50

0022-5223/\$36.00

Copyright (C) 2011 by The American Association for Thoracic Surgery

doi:10.1016/j.jtcvs.2011.02.032 is pulled out, making it right-side-out again (Figures $1, D$, and $2, C$ ), and then cut so that $5 \mathrm{~mm}$ of the length remains. Next, a composite graft with a short flange or a stentless aortic valve is sewn to the graft anastomosed to the LVOT with a continuous suture (Figure 1,E). Coronary ostia are reimplanted into the composite graft by using either the button technique or the graft $(10 \mathrm{~mm})$ interpose technique (Figure 1,F). Finally, the distal end of the composite graft is anastomosed to the ascending aorta.

Since 2002, we have performed aortic root replacement with this technique in 6 complicated reoperations: 2 pseudoaneurysms and 1 bioprosthetic valve failure after aortic root replacement and 3 cases of PVE (mechanical valve, $\mathrm{n}=2$; stentless bioprosthetic valve, $\mathrm{n}=1$ ). The grafts that were used for redo surgery were composite grafts with a mechanical valve in 2 cases, a composite graft with a stented bioprosthetic valve in 1 case, and stentless aortic valves in 3 cases. Concomitant procedures were tricuspid valve repairs in 2 cases and quadruple coronary artery bypass grafting in 1 case. Mean crossclamp and cardiopulmonary bypass times were $189 \pm 44$ and $279 \pm 38$ minutes, respectively. No additional stitching was necessary for hemostasis of the proximal anastomosis in any patient. No complete heart block or re-exploration was seen. During the mean followup time of $52 \pm 31$ months, there was 1 early death caused by respiratory failure and 1 late death caused by liver cirrhosis 41 months after surgical intervention. None of the patients have undergone a further reoperation for any cause.

\section{DISCUSSION}

Bleeding from the proximal anastomosis is the most common complication in reoperation on the aortic root. It has been reported that the incidence of early reintervention for excessive bleeding is high $(5 \%$ to $15 \%))^{1,2}$ In reoperation the aortic annulus and surrounding tissue are often irregular and insecure for performing a proximal anastomosis because of adhesion, inflammation, or debridement. We therefore created a graft insertion technique for the proximal anastomosis for such complicated cases. This technique is 